\title{
THE SOUNDSCAPE APPROACH FOR THE ASSESSMENT AND CONSERVATION OF MEDITERRANEAN LANDSCAPES: PRINCIPLES AND CASE STUDIES
}

\author{
Almo FARINA $^{* 1}$, GIUSEPPA BusCAINO ${ }^{2}$, MARIA CERAUlO ${ }^{1,2}$, NADIA PIERETTI $^{1}$ \\ ${ }^{I}$ Department of Basic Sciences and Foundations - University of Urbino - Campus \\ Scientifico 'Enrico Mattei' - Urbino, Italy, e-mail: almo.farina@ uniurb.it \\ ${ }^{2}$ National Research Council - Institute for Coastal Marine Environment, Capo Granitola - \\ 91021 T.G. Campobello di Mazara (TP) - Italy
}

Received: $20^{\text {th }}$ March 2014, Accepted: $25^{\text {th }}$ June 2014

\begin{abstract}
The fine-grained mosaic of natural and human-modified patches that characterizes the Mediterranean region has created a multifaceted system that is difficult to investigate using traditional ecological techniques. In this context, sounds have been found to be the optimum model to provide indirect and timely information about the state of ecosystems. The sonic nature of the environment (the soundscape) represents an important component of the landscape, and the new discipline of soundscape ecology has recently been shown to have appropriate tools for investigating the complexity of the environment. In the last decade, technological advances in the acoustic field have led researchers to carry out wide-scale and long-term ecological research using new and efficient tools, such as digital low cost sound recorders, and autonomous software and metrics. Particularly in the Mediterranean region, where land transformation occurs at a very rapid rate, soundscape analysis may represent an efficient tool with which to:1) track transformations in the community balance, 2) indicate the most acoustically complex parts (bioacoustic hotspots) of the land mosaic, 3) prevent environmental degradation, and 4) decide whether protection or restoration actions are most appropriate.
\end{abstract}

Conserving the quality of Mediterranean sounds means preserving the natural dynamics of its animal populations and also involves maintaining the cultural heritage, human identity, and the spiritual values of the area.

Keywords: soundscape ecology, Mediterranean landscape, sonotope, soundtope, acoustic diversity, conservation.

\section{INTRODUCTION}

According to the European Landscape Convention (Council of Europe, 2000), the Mediterranean region and its cultural landscapes represent an important recreational, aesthetic and spiritual resource that must be preserved from the risk of degradation in the present time.

In the distant past, the Mediterranean region was mainly managed by pastoralism and agriculture practices, which lasted for thousands of years (Grove \& Rackham, 2003) 
generating a complex system in which plants, animals, humans and crops have been coevoluted generating landscapes rich of ecological interactions (Naveh \& Carmel, 2003). However, there have been dramatic changes to landscape structure and functioning over the last few decades caused by urban sprawl (Munoz, 2003; Catalan et al., 2008), expansion of transportation infrastructure and airplane transits, uncontrolled hazardous waste disposal, the degradation of coastal systems by tourist settlements and harbors (e.g. Salvati \& Zitti, 2008; Hepcan et al., 2013), and the significant reduction of the fish stock (e.g. LLeonart \& Maynou, 2003). Moreover, economic and social changes over the last 50 years have produced diffuse land abandonment in some parts of the Mediterranean, especially along mountainous areas (e.g. Vos \& Stortelder, 1992) causing increased soil erosion (Koulouri \& Giorgua, 2007; Pardini et al., 2003) and changes to the fire regime (Naveh, 1975; Brotons et al., 2013).

In normal planning practice, landscape quality is assessed after several concurrent geographical, ecological, and aesthetic factors have been surveyed and taken under analysis (Naveh \& Lieberman, 1984; Forman \& Godron, 1986). Among the different descriptors of the landscape characters (e.g. the presence of scenic views, historical landmarks, distribution of natural vegetation, the structure of rural spaces, patch mosaics), the sonic environment or soundscape has, until recently, often been neglected or only marginally considered.

The sounds produced in the environment by geophysical (geophonies), biological (biophonies) and anthropogenic (technophonies) processes have been found to be an important indicator of the quality of a system (Schafer, 1977). By not using the sonic approach, primary information on the functioning of environments is ignored or underestimated, thus risking the loss of data that are critical for conservation purposes (Farina \& Pieretti, 2012). Recent developments in soundscape analysis have demonstrated the existence of a strict connection between ecology and sounds (Farina, 2014); the investigation of the acoustic patterns may represent a unique methodology for assessing the complexity of ecosystems (Matsinos et al., 2008; Servick, 2014).

The principles guiding soundscape ecology are the result of the contribution of different concurrent disciplines, specifically landscape ecology, bioacoustics, psychoacoustics, and acoustic ecology (Pijanowski et al., 2011). The primary goals of this discipline are to 1) Develop a deeper comprehension of the natural dynamics of ecosystems, 2) Preserve sounds as a natural and cultural resource, 3) Investigate long-term sound dynamics with respect to climate and other human-mediated alterations, and 4) Evaluate the capability of acoustic diversity to be used as a proxy for biodiversity (Sueur et al., 2008).

Acoustic diversity has been considered to be a good proxy for overall vocal animal richness (Depraetere et al., 2012). In fact, recent research has demonstrated that when more species are present within a community, there is an increase in diversity of signals across the spectrum of frequencies. Birds, mammals, amphibians, fish, and arthropods all produce sounds, especially during the breeding period (Bradbury et al., 1998), to communicate, attract mates, establish and defend their territory, send out alarms to predators, and to socialize. Consequently, analyzing these proxies via the use of specific indices could help to map hotspots of functional biodiversity (Pekin et al., 2012). In particular due to the great heterogeneity of Mediterranean landscapes (mainly due to human-induced alteration), there is a soundscape with a fine spatial and temporal resolution, and a result of this parallel behavior of sounds to landscape structure, soundscape indices (such as acoustic complexity or diversity) will be important indicators for ecosystem dynamics across human-dominated, complex landscapes.

In recent times, everywhere across the Mediterranean, the sounds of the natural environment and agricultural lands have increasingly been overlapped, masked and degraded by sounds produced by industrial machinery, vehicles on transportation infrastructures, and 
Farina A., Buscaino G., Ceraulo M., Pieretti N.: The soundscape approach for the assessment and conservation of Mediterranean landscapes: principles and case studies.

the sounds that emerge from the 'metabolism' of urban areas. Nowadays, 'acoustic pollution' represents a major element of land degradation, and is often one of the major causes of ecosystem malfunctioning that is perceived as a threat to a region like the Mediterranean regarded as a hot spot for biodiversity (Myers et al., 2000; Blondel et al., 2010).

Sounds are also fundamental components of freshwater and marine systems (Trenkel et al., 2011; Yan et al., 2010). Water is an excellent medium for sound transmission because it travels about five times faster in water than in air (about $1500 \mathrm{vs.} 300 \mathrm{~m} / \mathrm{s}$ ) and attenuates less over the same distances in water than in air. As a consequence, sound travels greater distances with higher amplitudes in water as compared to air, thereby enabling long-distance communication, which may also have greater impacts on aquatic animals. Aquatic system degradation arises from environmental problems that are similar to or worse than those facing terrestrial landscapes (e.g. Codarin et al., 2009; Slabbekoorn et al., 2010). Indeed, the ecosystem balance of coastal waters along the Mediterranean Sea is also severely threatened by human-produced sounds coming from tourist boats, merchant vessels (the Mediterranean Sea is one of the most densely trafficked sea in the world), fishing activities (Frisk, 2012), and sounds of various types of underwater measurement involving both low and high frequencies (Slabbekoorn et al., 2010). Accordingly, the conservation of Mediterranean ecosystems means passing through the interaction between terrestrial and aquatic (freshwater and marine) soundscapes.

The aims of this paper should be viewed within this context, and involve illustrating the great potential of the soundscape approach when it comes to investigating Mediterranean environmental complexity and producing guidelines for the more efficient protection of the ecological and cultural processes that are relevant to the ethical and sustainable use of resources. Principles, methodologies and potential applications of soundscape ecology to the conservation of the Mediterranean landscapes are presented and discussed here.

\section{PRINCIPLES OF SOUNDSCAPE ECOLOGY}

\section{The three components of the soundscape}

According to Krause (1987), the soundscape is the result of three major sources of sound: geophonies, biophonies and anthropophonies or technophonies. Geophonies are produced by natural agents like wind, rain, water flow, or volcanoes. Biophonies, meanwhile, are represented by organismic calls, alarms and songs produced by specific organs, such as the syrinx in birds, vocal folds in terrestrial mammals, and stridulation organs in insects (f.i the 'scraper' or plectrum and the 'file' or stridulitrum). Technophonies are the result of human-made sounds generated from cars, trains, vessels, airplanes, and various other industrial and domestic devices.

These three different sources of sound blend together in different percentages according to the environmental features; for instance, in urban areas, technophonies are dominant, while in remote forests, biophonies are the major component of a soundscape. The proportion of technophonies present within the soundscape also determines its quality. For instance, a high-fidelity (Hi-Fi) sonic environment is characterized by the ability of a listener to easily distinguish various sounds from one another (a quiet location without covering noises), where as a low-fidelity (Lo-Fi) sonic environment has a level of noise that impedes the capacity for listeners to distinguish between various sounds comprising the soundscape (e.g. in an overcrowded room, a railway station, or close to an airport) (Truax, 1999).

The combination of geophonies, biophonies and technophonies creates a sonic environment that is heterogeneous in space and time, which we define here as a 'sonotope' 
(Farina, 2014; p. 17). This repartition in time and space is further distinguished into sub-components termed 'soundtopes', which are defined as voluntarily organized (coordinated) assemblages of vocalizing animals (Farina, 2014; p. 17). This sonic aggregation is mainly driven by behavioral processes that occur at the intra- and inter-specific levels, and largely depends on community diversity and local species abundance. The soundtope changes according to the season and the weather conditions, as recently described by Farina \& Pieretti (2013) who used an array of microphones positioned in a Mediterranean maquis.

When different soundtopes meet, as in the case of a heterogeneous landscape, we expect a tension zone that could be defined as an acoustic ecotone where information is exchanged between the two or more adjacent soundtopes. According to Farina (2014, p. 20), these special areas are called 'sonotones' and strongly match the acoustic complexity of a landscape.

\section{The soundscape as a resource}

Soundscape studies are recognized today as an important natural resource (Farina 2011) for animals as well as people (Carles et al., 1999; Dumyahn \& Pijanowski, 2011); albeit recently neglected or considered to be a marginal attribute in both landscapes and seascapes. The soundscape particularly needs to be protected in national parks and reserves (Iglesias Mercahn et al., 2014); however, sound consciousness has been rising, including among citizens, who share a growing concern about the preservation of the high quality soundscapes of their living space. The reduction of acoustic annoyances is thus an important goal in urban planning (Jeon et al., 2010). The importance of the soundscape is emphasized by the recent Careggi declaration by UNISCAPE (the Network of Universities especially dedicated to the implementation of the European Landscape Convention, http://www. uniscape.eu) on their protection that underlines the need to incorporate a sound quality assessment when seeking to influence relevant stakeholders' decisions. Moreover, the European Marine Strategy Framework Directive (adopted in June 2008) aims to achieve a good environmental status with respect to the EU's marine waters by 2020, and includes underwater marine noise as an impact factor.

The sounds of nature can have an important role in the evaluation of the quality of a place. Sounds may represent a spiritual resource and in several cases are valued as a tourist attraction (O'Connor, 2008). When unwanted, sound is considered to be a noise and, if its intensity is too high or its duration too long, this can create health problems in humans (Kawada, 2011) but also physiological stress in wild animals (Creel et al., 2002). The soundscape acts as an informative environment for animals (Brumm \& Slabbekoorn, 2005), as well as also being necessary for maintaining a communication flux between individuals and groups (Laiolo, 2010) where a great deal of time and energy is expended performing single songs or collective choruses (Burt \& Vehrencamp, 2005).

\section{The relationship between landscape and soundscape}

The soundscape and landscape are strictly related and, although apparently linked by the transmission of sound across the environment, these two 'objects' are not expected to be coincident in space (Truax \& Barrett, 2011). Three theoretical models are proposed by Farina (2014, p. 21) to explain the relationship between landscapes and soundscapes. The first model assumes an exact coincidence between the sonotopes and the land mosaic edges, while the second foresees that the edges of the sonotopes are not coincident with the edges of the land mosaic. Finally, on the basis of the third model, the sonotopes are finer grained than the land mosaic. This last model is particularly interesting for ecologists since, if demonstrated to 
Farina A., Buscaino G., Ceraulo M., Pieretti N.: The soundscape approach for the assessment and conservation of Mediterranean landscapes: principles and case studies.

be accurate, will assign to the soundscape the role of indicator of landscape heterogeneity. In fact, it has been well-documented that sounds are sensitive to several physical features such as temperature, humidity, vegetation cover, typology, and distance from noise sources (see, for instance, Morton, 1975).

\section{INSTRUMENTS WITH WHICH TO COLLECT THE SOUNDSCAPE}

Recent developments in digital technology enable the easy transfer of sounds from diverse sources. Digital recorders and high quality microphones are available today at a moderate cost. In particular, a new generation of low cost digital recorders (LCR; Farina et al., 2014) represents a new frontier of sound monitoring. In the near future, recording devices costing less than 100 USD will compete with more expensive devices (600-900 USD), enabling there to be more concurrent sampling points for a very low financial investment that can fit into any budget. Digital memory cards can efficiently store high density information $(8,16,32$ and $128 \mathrm{~GB}$ or more). Moreover, the possibility that recorders will be programmable in terms of both time (setting prefixed times at which the device starts and stops recording) and frequency (high-pass and low-pass pre-filters of sound), coupled with the option to process data in real-time with remote downloads (via Wi-Fi), opens the way to a very efficient system to collect acoustic information without consuming much power (Lattanzi \& Bogliolo, 2012).

The opportunity to sample at a large scale resolution and repeatedly overtime inevitably produces massive amounts of data that needs to be acoustically verified before a numerical processing. To avoid time-consuming analyses, new methods to transform the acoustic information into numerical values and clarify the data are needed. The entropy index, based on the Shannon algorithm (Sueur et al., 2008), represents a good metric to assess acoustic diversity and has been interpreted as a proxy for estimating biodiversity. The Acoustic Complexity Index (Farina \& Morri, 2008; Pieretti et al., 2011) is another metric that is commonly used to describe the complexity of a soundscape by calculating the differences in amplitudes recorded in selected frequency bands. The amount of information provided by these quick and immediate algorithms has shown to be good indicators of acoustic diversity and, consequently, a proxy for species richness.

The efficient handling of acoustic files by dedicated software (such as the Soundscape Meter; Farina et al., 2012) enables unwanted frequencies to be excluded, the noise of the environment to be filtered, and a sound file to be investigated at different temporal and frequency resolutions. Other software (such as ARBIMON) can learn to automatically recognize certain species calls or songs, even among intense choruses (Aide et al., 2013). New procedures and algorithms are in the process of being produced to enable the acoustic complexity of an environment to be understood in detail. For instance, a numeric process that enables users to select different thresholds of acoustic amplitude has recently been developed in order to distinguish sounds emitted from a distance (far-field) versus closer to microphones (fore-field). More precisely, the fore-field is distinguished by a high level of acoustic amplitude, meaning that vocalizing individuals are very close to the recording microphone/hydrophone. On other hand, the far-field, which is characterized by low acoustic amplitudes, is generated by vocalizing individuals positioned far away from the microphones. When an array of microphones is used, it is possible to assess the distribution of individual species across an area and, in this way, calculate the beta diversity (Whittaker, 1960) of sound among different sites. This methodological approach is important, especially in the Mediterranean landscapes where environmental heterogeneity prevents the estimation of diversity by using only vegetation criterion. 


\section{THE APPLICATION OF SOUNDSCAPE ECOLOGY TO PROTECT THE MEDITERRANEAN LANDSCAPE AND SEASCAPE}

It is well known from the literature that a degraded landscape usually has a very poor soundscape, while, an intact landscape often presents a richer soundscape. Based on this assumption, the application of soundscape analysis to the Mediterranean landscape seems to be extremely promising for conservation purposes. In particular, the evaluation of the complexity of a landscape can be easily achieved using passive recording devices that are capable of collecting information on the complexity of the soundscape. The comparison between sound characteristics and the vegetation structure can be used to evaluate the level of connectivity in a patchy mosaic, or the influence of vegetation on the soundscape. For instance, in a Mediterranean maqui of northern Italy along the Tyrrhenian coast, Farina \& Pieretti (2013) found that the distributions of certain types of vegetation cover (Erica arborea) are associated with a higher value of acoustic complexity.

Particularly in the Mediterranean region, where land transformation occurs at a very rapid rate, soundscape analysis may represent an efficient tool with which to:1) track transformations in the community balance, 2) indicate the most acoustically complex parts (bioacoustic hotspots) of the land mosaic, 3) prevent environmental degradation, and 4) decide whether protection or restoration actions are most appropriate. New generations of low cost recorders will increase the opportunity to collect acoustic information over large areas, and will also offer additional possibilities to process acoustic files in real-time; thus, enabling the investigation of larger regions with arrays of acoustic data loggers (LCR). Moreover, the quality of a soundscape can be assessed in large regions to obtain more general indications for future development (Mazaris et al., 2009; Papadimitriou et al., 2009).

In the Mediterranean region, the terrestrial soundscape constitutes only one part of the story; marine systems offer a great collection of seascapes at every depth, which are associated with an idiosyncratic soundscape, suggested by recent investigations along the Adriatic coasts and in the Sicily Channel.

Acoustic complexity of underwater ecosystems in the Mediterranean is poorly understood (Buscaino et al.; in preparation); however, a recent study concerning the Atlantic Ocean noted that different ecosystems produce different soundscapes (McWilliam \& Hawkins, 2013). Particularly in marine environments, where visual and chemical cues disappear quickly, the acoustic exploration of marine systems either close to the coast, where the posidonia kelps (Posidonia oceanica (L.) Delile) rises, or in the deep waters where dolphins and other cetaceans produce a great variety of sounds, seems to provide relevant information that is fundamental for conservation.

Because sounds travel faster in water than in air, sounds may be used more by marine animals than terrestrial species for communication, mating, orientation (Simpson et al., 2005), and seeking appropriate habitats. Historically, most conservation work has focused on terrestrial systems (Myers et al., 2000), but in recent decades, it has seemed increasingly evident that conservation efforts were also urgently needed for the marine environment (Myers et al., 1997; Casey \& Myers, 1998; UE Marine Strategy). Lately, marine systems have been ever more affected by human activities (over-exploitation, eutrophication, pollution, and invasive species introductions (Burrows et al., 2011; Halpern et al., 2008; Hoegh-Guldberg \& Bruno, 2010). These stressors produced documented changes in species composition and richness (Beaugrand et al., 2010; Byrnes et al., 2007; Dulvy et al., 2003; Hawkins et al., 2009; Sax \& Gaines, 2003). To minimize the consequences of such major human intrusion, a great deal of effort has been made to establish marine reserves (Boersma \& Parrish, 1999; Mangel, 2000) that are selected according to specific criteria necessary for 
Farina A., Buscaino G., Ceraulo M., Pieretti N.: The soundscape approach for the assessment and conservation of Mediterranean landscapes: principles and case studies.

species survival, which include: food, mating potential, refuge availability, the chemical characteristics of the water, and unaltered remnant habitats, etc.

About 1000 marine protected areas (MPAs) have been established in the Mediterranean Sea (Garcia-Charton et al., 2008; Guidetti et al., 2008). However, these MPAs cover only $0.4 \%$ of this sea (Abdulla et al., 2009), meaning that further work has been urgently demanded by the Strategic Plan for Biodiversity (Perrings et al., 2010) to achieve the goal of protecting a minimum of $10 \%$ of coastal and marine areas by 2020. David Mouillot et al. (2011) have argued that, despite its relatively small size, the Mediterranean MPA system is spatially congruent with hot spots of taxonomic fish diversity, although this system completely misses verified hot spots of functional diversity. This lacuna largely comes from gaps in detailed and spatially explicit regional-scale data sets (Rodrigues et al., 2004).

One of most powerful tools for monitoring dynamic oceanographic features and potential biological hot spots over a wide range of spatial and temporal scales is the analysis of the marine dynamics by using satellite images (e.g. Mumby \& Harborne, 1999; Palacios et al., 2006; Zainuddin et al., 2006). Nevertheless, satellite data have several limitations (Palacios et al., 2006), such as the opportunity to only scan an area with discernible physical characteristics (eddies, meanders, fronts), impeding the tracking of biological dynamics operating in deep waters. A second limitation is the inability to directly observe biological processes, while weather conditions also limit the ability to acquire a number of relevant parameters, such as sea surface temperatures and phytoplankton chlorophyll-16 concentration.

Soundscape analysis offers an efficient and complementary, alternative approach to these remote sensing methods. Sound travels fast through water (Urick, 1983) and is capable of conveying significant information over long distances. Many marine organisms make sounds: marine mammals (Erbe, 2012; Richardson et al., 1995; Southall et al., 2007; Tyack \& Clark, 2000), fish (Bass \& Ladic, 2008; Popper et al., 2003; Hawinks \& Myrberg, 1983; Myrberg, 1978, 1980; Tavolga, 1971) and invertebrates (Buscaino et al., 2011; Popper et al., 2001). These organisms reveal their presence and behavioral dynamics through acoustic signals that can be easily detected, recorded, saved, and analysed.

\section{CONCLUSIONS AND RECOMMENDATIONS}

Today, the emergent discipline of soundscape ecology offers efficient tools to optimize the protection of the Mediterranean landscape, attracting scientists from multifaceted disciplines, cultural backgrounds, and with different philosophical visions. The soundscape approach allows the advantageous exchange of knowledge and the integration of a separate chapter of information by establishing bridges of knowledge and experience. This leads to the enhancement of emergent properties from landscapes and seascapes, which would alternatively be at risk of passing unnoticed. The opportunity to evaluate the acoustic processes of natural and anthropogenic sources opens up a grand vista to the complex environmental scenario across the Mediterranean basin. The cultural, historical, political and economic heterogeneity of this region can also be efficiently described and tracked over the years using soundscape analysis.

Acoustic communication is a fundamental component for both animals and humans. The recent challenge posed by forthcoming and, in some measure, actual climate change can be observed and analyzed through a passive listening methodology, which is constantly improving in terms of technology advancement and accessibility for several categories of users. Thanks to new advances in recording equipment and the opportunity to opt for low 
cost instruments, the passive recording of the voice from nature is a remarkable tool for gaining knowledge on animal and human societies. It is also an affordable guide to conservation planning and management. This is particularly true in the Mediterranean region, where the complexity of natural systems coupled with the extraordinary local identity of people represents a unique scenario. From this perspective, teaching people to listen to the soundscape becomes a priority at every level of the education system, and the improvement of ear-based perspectives (sensu Schafer, 1977) is a useful and democratic exercise.

\section{REFERENCES}

Abdulla, A., Gomei, M., Hyrenbach, D., Notarbartolo-Di-Sciara, G., Agardy, T., (2009). Challenges facing a network of representative marine protected areas in the Mediterranean: Prioritizing the protection of under represented habitats ICES. J. Mar. Sci., 66: pp. 22-28.

Aide, T.M., Corrada-Bravo, C., Campos-Cerqueira, M., Milan, C., Vega, G. \& Alvarez, R., (2013). Real-time bioacoustics monitoring and automated species identification. PeerJ, 1, e103.

Bass, A.H., Ladich F., (2008). Vocal-acoustic communication: From neurons to behavior. In: Webb, F.J., Fay, R.R., Popper, A. (Eds.): Fish bioacoustics (pp. 253-278). Springer - New York.

Beaugrand, G., Edwards, M., Legendre, L., (2010). Marine biodiversity, ecosystem functioning and carbon cycles. Proceedings of the National Academy of Sciences 107 (22): 10120-10124.

Blondel, J., Aronson, J., Bodiou, J-Y, Boeuf, G., (2010). The Mediterranean Region. Biological Diversity in Space and Time. Oxford University Press, Oxford.

Boersma, P. D., Parrish, J.K., (1999). Limiting abuse: marine protected areas, a limited solution. Ecological Economics 31(2): 287-304.

Bradbury, J.W., Vehrencamp, S.L., (1998). Principles of animal communication. Sunderland, Massachusetts: Sinauer Associates.

Brotons, L., Aquilué, N., De Cáceres, M., Fortin, M-J., Fall, A., (2013). How fire history, fire suppression practices and climate change affect wildfire regimes in Mediterranean Landscapes. PLOS ONE DOI: 10.1371/journal.pone.0062392

Brumm, H., Slabbekoorn, H., (2005). Acoustic communication in noise. In: Slater, P.J.B., Snowdon, C.T., Roper, T.J., Brockmann, H.J., Naguib, M. (eds.) Advance in the study of behavior (pp. 151-209). Elsevier, vol. 35.

Burrows, M. T., Schoeman, D. S., Buckley, L. B., Moore, P., Poloczanska, E. S., Brander, K. M., Brown, C., Bruno, J. F., Duarte, C. M., Halpern, B. S., Holding, J., Kappel, C. V., Kiessling, W., O'connoR, M. I., Pandolfi, J. M., Parmesan, C., Schwing, F. B., Sydeman, W. J. and Richardson, A., J., (2011). The Pace of shifting climate in marine and terrestrial ecosystems. Science 334: 652-655.

Burt, J. M., Vehrencamp, S. L., (2005). 15. Dawn chorus as an interactive communication network. In: McGregor, P.K. (ed.): Animal Communication Networks (pp. 320-343). Cambridge University Press, Cambridge, UK.

Buscaino, G., Filiciotto, F., Gristina, M., Bellante, A., Buffa, G., Di Stefano, V., Maccarrone, V., Tranchida, G., Buscaino, C., Mazzola, S., (2001). Acoustic behaviour of the European spiny lobster Palinurus elephas Mar. Ecol. Prog. Ser., 441:177-184 
Farina A., Buscaino G., Ceraulo M., Pieretti N.: The soundscape approach for the assessment and conservation of Mediterranean landscapes: principles and case studies.

Byrnes, E.J., Reynolds, L.P., Stachowicz, J.J., (2007). Invasions and extinctions reshape coastal marine food webs. PLoS One 2.3: e295.

Carles, J.L., Lopez Barrio, I., De Lucio, J.V., (1999). Sound influence on landscape values. Landscape and Urban Planning 43: 191-200.

Casey, J.M., Myers, R.A., (1998). Near extinction of a large, widely distributed fish. Science 281 690-692.

Catalan, B., Saury, D., Serra, P., (2008). Urban sprawl in the Mediterranean? Patterns of growth and change in the Barcelona Metropolitan Region 1993-2000. Landscape and Urban Planning 85: 174-184.

Codarin, A., Wysocki, L.E., Ladich, F., Picciulin, P., (2009). Effects of ambient and boat noise on hearing and communication in three fish species living in a marine protected area (Miramare, Italy). Marine Pollution Bulletin 58: 1880-1887.

Creel, S., Fox, J.E., Hardy, A., Sands, J., Garrot, B., Peterson, R.O. (2002). Snowmobile activity and glucocorticoid stress responses in wolves and elk. Conservation Biology 16(3): 809-814.

Depraetere, M., Pavoine, S., Jiguet, F., Gasc, A., Duvail, S., Sueur, J., (2012). Monitoring animal diversity using acoustic indices: implementation in a temperate woodland. Ecological Indicators 13 (1): 46-54.

Dulvy, N.K., Sadovy, Y., Reynolds, J.D. (2003). Extinction vulnerability in marine populations. Fish and Fisheries 4(1): 25-64.

Dumyahn, S.L., Pijanowski, B.C., (2001). Beyond noise mitigation: managing soundscapes as common-pool resources. Landscape ecology 26 (9): 1311-1326.

Erbe, C., (2012). Effects of underwater noise on marine mammals. In: Popper, A., Hawkins, A. (Eds.): The Effects of Noise on Aquatic Life (pp. 17-22). Springer, New York.

Farina, A., (2011). A biosemiotic perspective for a Resource Criterion: Toward a General Theory of Resources. Biosemiotics 5:17-32.

Farina, A., (2014). Soundscape ecology. Springer, Dordrecht, NL.

Farina, A, Morri, D., (2008). Source-sinke eco-field: ipotesi ed evidenze sperimentali. Atti del X Congresso nazionale della SIEP-IALE. Ecologia e governance del paesaggio: esperienze prospettive. Universita` degli Studi di Bari, Politecnico di Bari. p. 365-372.

Farina, A., Pieretti, N., (2012). The soundscape ecology: A new frontier of landcape research an its application to islands and coastal systems. Journal of Marine and Island Cultures 1:21-26.

Farina, A., Lattanzi, E., Piccioli, L., Pieretti, N., (2012). The Soundscape Meter User Manual. Retrieved March 30, 2013, from: www.disbef.uniurb.it

Farina, A., Pieretti, N., (2013). Sonic environment and vegetation structure: A methodological approach for a soundscape analysis of a Mediterranean maqui. Ecological Informatics. Retrieved March 30, 2013, from: http://dx.doi.org/10.1016/j.ecoinf.2013. 10.008

Farina, A., James, P., Bobryck, C., Pieretti, N., Lattanzi, E., McWilliam, J., (2014). Lowcost (audio) recording (LCR) for advancing soundscape ekology towards the conservation of sonic complexity and biodiversity in naturaland urbanlandscapes. Urban Ecosyst. DOI 10.1007/s11252-014-0365-0

Forman, R.T.T., Godron, M., (1986). Landscape Ecology. Wiley, NY. 
Frisk, G. V., (2012). Noiseonomics: The relationship between ambient noise levels in the sea and global economic trends. Scientific Reports, 2, Article number 437, doi:10.1038/srep00437

Garcia-Charton, J.A., Perez-Ruzafa, A., Marcos, C., Claudet, J., Badalamenti, F., Benedetti-Cecchi, L., Falcon, J.M., Milazzo, M., Schembri, P.J., Stobart, B. et al. (2008). Effectiveness of European Atlanto-Mediterranean MPAs: Do they accomplish the expected effects on populations, communities and ecosystems? J. Nat. Conserv. 16:193-221.

Grove, A.T., Rackham, O., (2003). The nature of Mediterranean Europe. Yale University Press, New Haven, CT.

Guidetti, P., Milazzo, M., Bussotti, S., Molinari, A., Murenu, M., Pais, A., Spano, N., Balzano, R. , Agardy, T., Boero, F. et al. (2008). Italian marine reserve effectiveness: Does enforcement matter? Biol.Conserv. 141: 699-709.

Halpern, B.S., Walbridge, S., Selkoe, A.K., Kappel, V.C., Micheli, M., D'Agrosa, C., Bruno, J.F. et al., (2008). A global map of human impact on marine ecosystems. Science 319 (5865): 948-952.

Hawkins, A.D., Myrberg, A.A., (1983). Hearing and sound communication under water. Bioacoustics, a comparative approach. Academic Press, London. pp. 347-405.

Hawkins, S. J., et al. (2009). Consequences of climate-driven biodiversity changes for ecosystem functioning of North European rocky shores. Marine Ecology Progress Series 396: 245-259.

Hepcan, S., Hepcan C.C., Kilicaslan, C., Ozkan, M.B., Kocan, N., (2013). Analyzing landscape change and urban sprawl in a mediterranean coastal landscape: a case study from Izmir, Turkey. Journal of Coastal Research 22(2): 301-310.

Hoegh-Guldberg, O., Bruno, J.F., (2010). The impact of climate change on the world's marine ecosystems. Science 328(5985): 1523-1528.

Jeon, J.Y., Lee, P.J., You, J., Kang, J. (2010). Perceptual assessment of quality of urban soundscapes with combined noise sources and water sounds. J. Acoust. Soc. Am. 127(3): 1357-1366.

Iglesias, M.C., Diaz, B.L., Solino, M., (2014). Noise pollution in national parks: Soundscape and economic valuation. Landscape and Urban Planning 123: 1-9.

Kawada, T. (2011). Noise and health - Sleep disturbance in adults. J. Occup. Health 53: 413-416.

Koulouri, M., Giorgua, CH., (2007). Land abandonment and slope gradient as key factors of soil erosion in Mediterranean terraced lands. Catena 69: 274-281.

Krause, B. L., (1987). Bioacoustics, habitat ambience in ecological balance. Whole Earth Rev 57:14 - 18.

Laiolo, P., (2010). The emerging significance of bioacoustics in animal species conservation. Biological Conservation 143: 1635-1645.

Lattanzi, E., Bogliolo, A., (2012). Ultra-Low-Power Sensor Nodes Featuring a Virtual Runtime Environment. Proceedings of the IEEE International Conference on Communications (E2Nets - ICC-12).

Lleonart, J., Maynou, F., (2013). Fish stock assessments in the Mediterranean: state of the art. Scientia Marina 67 (Suppl. 1): 37-49.

Mangel, M., (2000). On the fraction of habitat allocated to marine reserves. Ecology Letters 
Farina A., Buscaino G., Ceraulo M., Pieretti N.: The soundscape approach for the assessment and conservation of Mediterranean landscapes: principles and case studies.

3(1): 15-22.

Matsinos, Y.G., Mazaris, A.D., Papadimitriou, K.D., Mniestris, A., Hatzgiannidis, G., Maioglou, D., Pantis, J.D., (2008). Spatio-temporal variability in human and natural sounds in a rural landscape. Landscape Ecology 23: 945-959.

Mazaris, A.D., Kallimanis, A.S., Chatzigianidis, G., Papadimitriou, K., Pantis, J.D., (2009). Spatiotemporal analysis of an acoustic environment: interactions between landscape features and sound. Landscape Ecology 24: 817-831.

McWilliam, J.N., Hawkins, A.D., (2013). A comparison of inshore marine soundscapes. Journal of Experimental Marine Biology and Ecology 446: 166-176.

Morton, E., (1975). Ecological sources of selection on avian sounds. Am. Nat. 109: 17-34.

Mouillot, D., et al., (2011). Protected and threatened components of fish biodiversity in the Mediterranean Sea. Current Biology 21(12):1044-1050.

Mumby, J.P., Harborne, R.A., (1999). Development of a systematic classification scheme of marine habitats to facilitate regional management and mapping of Caribbean coral reefs. Biological Conservation 88(2): 155-163.

Munoz, F., (2003). Lock living: urban sprawl in mediterrean cities. Cities 20: 381-385.

Myers, R.A., Hutchings, J.A., Barrowman, N.J. (1997). Why do fish stocks collapse? The example of cod in Atlantic Canada. Ecological Applications 7: 91-106.

Myers, N., R. A. Mittermeier, C. G. Mittermeier, G. A. B. Da Fonseca, and J. Kent, (2000). Biodiversity hotspots for conservation priorities. Nature 403:853 - 858.

Myrberg, A.A. JR., (1978). Ocean noise and the behavior of marine animals: relationships and implications. In: Fletcher, J.L., Busnel, R.G. (Eds.): Effects of Noise on Wildlife (pp. 169-208). Academic Press, New York.

Myrberg, A.A. JR., (1980). Fish bio-acoustics: its relevance to the 'not so silent world' Environ. Biol. Fish. 5:297-304.

Naveh, Z., (1975). The evolutionary significance of fire in the Mediterranean region. Vegetatio 29: 199-208.

Naveh, Z., Lieberman, A.S., (1984). Landscape ecology: theory and application. Springer Verlag, New York.

Naveh, Z., Caermel, Y., (2003). The Evolution of the cultural mediterranean landscape in Isreal as affected by fire, grazing, and human activities. In: S.P. Wasser (ed.): Evolutionary Theory and Processes: Modern Horizons, Papers in Honour of Eviatar Nevo (pp.337-409), Kluwer Academic Publishers, Dordrecht.

O'Connor, P., (2008). Sound of silence: valuing acoustics in heritage conservation. Geographical Research 46(3): 361-373.

Palacios, M.D., et al., (2006). Oceanographic characteristics of biological hot spots in the North Pacific: a remote sensing perspective. Deep Sea Research Part II: Topical Studies in Oceanography 53(3): 250-269.

Papadimitriou, K.D., Mazaris, A.D., Kallimanis, A.S., Pantis, J.D., (2009). Cartographic representation of the sonic environment. The Cartographic Journal 46(2): 126-135.

Pardini, G., Gispert, M., Dunjo, G., (2003). Runoff erosion and nutrient depletion in five Mediterranean soils of NE Spain under different land use. The Science of the Total Environment 309: 213-224.

Pekin, K.B., Pijanowski. C.B., (2012). Global land use intensity and the endangerment status 
of mammal species. Diversity and Distributions 18(9): 909-918.

Perrings, C., et al., (2010). Ecosystem services for 2020. Science 330 (6002):323-324.

Pieretti, N., Farina, A., Morri, D., (2011). A new methodology to infer the singing activity of an avian community: The Acoustic Complexity Index (ACI). Ecological Indicators 11(3): 868-873.

Pijanowski, B.C., Villanueva-Rivera, L.J., Dumyahn, S.L., Farina, A., Krause, B.L., Napoletano, B. M., Gage, S.H., Pieretti, N., (2011). Soundscape Ecology: The Science of Sound in the Landscape. BioScience 61:203-216.

Popper, A.N., Salmon, M., Horch, K.W., (2001). Acoustic detection and communication by decapod crustaceans. J. Comp. Physiol., 187:83-89.

Popper, A.N., Fay, R.R., Platt, C., Sand, O., (2003). Sound detection mechanisms and capabilities of teleost fishes. In: Collin, S.P., Marshall, N.J. (Eds.): Sensory Processing in Aquatic Environments (pp. 3-38), Springer-Verlag, New York.

Richardson, W.J., Greene, C.R. JR., Malme, C.I., Thomson, D.H., (1995). Marine mammals and Noise. Academic Press, New York.

Rodrigues, A.S.L., Andelman, S.J., Bakarr, M.I., Boitani, L., Brooks, T.M. , Cowling, R.M., Fishpool, L.D.C., DA Fonseca, Gaston, K.J., Hoffmann, M., et al., (2004). Effectiveness of the global protected area network in representing species diversity. Nature 428: 640-643.

Salvati, L., Zitti, M., (2008). Regional convergence of environmental variables: Empirical evidences from land degradation. Ecological Economics 68: 162-168.

Sax, D.F., Gaines, S.D., (2003). Species diversity: from global decreases to local increases. Trends in Ecology \& Evolution 18(11): 561-566.

Servick, K., (2014). Eavesdropping on Ecosystems. Science: 343 (6173), 834-837. [DOI:10.1126/science.343.6173.834]

Schafer, R.M., (1977). The soundscape: our sonic environment and the tuning of the world. Destiny Books. Rochester, NY. US.

Simpson, S. D., (2005). Homeward Sound. Science 308: 221-221.

Slabbekoorn, H., Bouton, N., Van Opzeeland, I., Coers, A., Ten Cate, C., Popper, A.N., (2010). A noisy spring: The impact of globally rising underwater sound levels on fish. Trends in Ecology and Evolution 25: 419-427.

Southall, B. L., Bowles, A.E., Ellison, W.T., Finneran, J.F., Gentry, R.L., Greene, C.R. JR, Kastak, D., et al., (2008). Marine mammal noise-exposure criteria: initial scientific recommendations. Bioacoustics 17, no. 1-3: 273-275.

Sueur, J., Pavoine, S., Amerlynck, O., Duvail, S., (2008). Rapid acoustic survey for biodiversity appraisal. PLOS ONE 3(12):e4065

Tavolga, W.N., (1971). Sound production and detection. In: Hoar. W.S ,. Randall, D.J (Eds.): Fish Physiology, vol. 5 (pp. 135-205), Academic Press, New York.

Trenkel, V.M., Ressler, P.H., Jech, M., Giannoulaki, M., Taylor, C., (2011). Underwater acoustics for ecosystem-based management: state of the science and proposals for ecosystem indicators. Marine Ecology Progress Series 442: 285-301.

Truax, B., (1999). Handbook for acoustic ecology. Cambridge Street Publishing.

Truax, B., Barrett, G.W., (2011). Soundscape in a context of acoustic and landscape ecology. Landscape Ecology 26: 1201-1207.

Tyack, P.L., Clark, C.W., (2000). Communication and acoustic behavior of dolphins and 
Farina A., Buscaino G., Ceraulo M., Pieretti N.: The soundscape approach for the assessment and conservation of Mediterranean landscapes: principles and case studies.

whales. In: Au, W.L., Popper, A.N., Fay, R.R. (eds.): Hearing by whales and dolphins (pp. 156-224), Springer New York.

Urick, J.R., (1983). Principles of underwater sound. McGraw-Hill, New York, London.

Vos, W., Sortelder, A., (1992). Vanishing Tuscan landscapes. Pudoc Scientific Publishers, Wageningen.

Whittaker, R.H., (1960). Vegetation of Siskiyou mountains, Oregon and California. Ecological Monographs 30: 279-338.

Zainuddin, M., et al. (2006). Using multi-sensor satellite remote sensing and catch data to detect ocean hot spots for albacore (Thunnus alalunga) in the northwestern North Pacific. Deep Sea Research Part II: Topical Studies in Oceanography 53(3): 419-431.

Yan, H.Y., Anraku, K., Babaran, R.P., (2010). Chapter 3 - Hearing in marine fish and its application in fisheries. In: He P. (Ed.): Behavior of marine fishes: capture processes and conservation challenges (pp. 45-64), Wiley-Blackwell, Ames, Iowa. 